\title{
Agriculture Monitoring and Smart Irrigation System Based on Wireless Sensors
}

\author{
S. Kannadhasan, M. Shanmuganantham \\ Department of Electrical and Electronics Engineering, Tamilnadu Government Polytechnic College, Madurai, India
}

Email address:

kannadhasan.ece@gmail.com (S. Kannadhasan), shammu1968@gmail.com (M. Shanmuganantham)

\section{To cite this article:}

S. Kannadhasan, M. Shanmuganantham. Agriculture Monitoring and Smart Irrigation System Based on Wireless Sensors. International Journal of Sensors and Sensor Networks. Special Issue: Sensors in the Field of Electrical and Electronics. Vol. 7, No. 4, 2019, pp. 51-55. doi: $10.11648 /$ j.jijssn.20190704.11

Received: September 23, 2019; Accepted: October 22, 2019; Published: November 8, 2019

\begin{abstract}
Automation facilitates the world for us. In this paper we have done it for making easy for farmers. Nowadays irrigation process has been converted as a complex process. Because of less manpower is available for low paid jobs like these. Not only man power but also time and over exploitation of energy made this problem as a bulk one for former. So automation of irrigation system is needed to overtake these problems. In our project we have done the total irrigation system as a non human interface system by using PLC (Programmable Logic Device). PLC contains lot of relay switches which are turned on or off by some logic. So we can use the PLC as an intelligent system which controls all devices. In this process all fields are irrigated one by one. Water level sensors are used to detect the required water level in the field and send the signals to the PLC. PLC closes the corresponding field's solenoid valve and opens the next field's valve. PLC saves the water during rain time by the way of switching off the motor. It saves the motor during drought period (i.e. if the water level decreases in the well). The irrigation process can be automated continuously for an over a period of time by using timers in the PLC. This type of automation is high sensitive compare to other because of intelligent PLC.
\end{abstract}

Keywords: Level Sensor, Rain Sensor, PLC, Water Flow

\section{Introduction}

Irrigation is the inevitable process for all crop fields. Still now there is no sufficient method for irrigation process. Irrigation process should be done with concerning all factors which define the economic status of the former [1-5]. Man power of India is high, but for low paid jobs there are no sufficient amounts of people. Manual method of irrigation causes over exploitation of natural resources. It leads to the time and money consumption more. It may destroy the crops because of over or low irrigation process which is because of the absence of the intellect of the former [6-8]. So automated irrigation system used PLC control makes the irrigation process as a simple one. Since we concerned the paddy fields where should be maintained the water level and the timing irrigation process $[9,10]$. But this system can be integrated for all type of agricultural lands in future because of the artificial intelligence of the system.

In many villages which are the backbone of India, there is no awareness about the automation interference in agriculture. Technical people have been supplementing the automation in agriculture slowly [11]. The conventional method of irrigation causes the over exploitation of water, electricity. It leads to the high investment and care about the irrigation process because of less man power whose are needed for these kind of jobs [12-14]. It may create inevitable defects in the motor which cannot be stopped at right point of time. 


\section{Block Diagram}

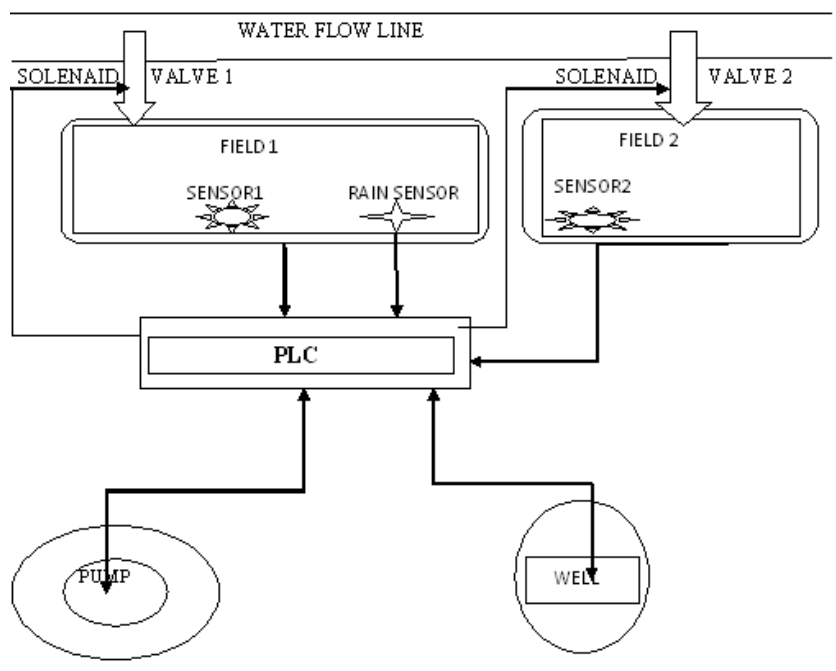

Figure 1. Block diagram of PLC based Sensor.

\section{Level Sensors}

Level sensors are used for only the paddy fields. For all types of fields moisture sensor can be used. Here we have concerned Level sensors which are used to sense the water level in the field. After the sensing the level they will transmit the signal to the PLC control unit. The transmission is done by using wireless network. The water level sensor is made under the conductivity principle. One contact is placed inside of the water and another one is placed in certain height which is the required level. If the water level touches the upper contact, then the sensor circuit will be activated and the signal from sensor is send to the PLC control unit by two ways.

1. Thorough wires

2. Wireless connection

In the first type may increase the cost when we go for large scale automation. But the wireless signal transmitting is feasible for large scale automation. In this type the signal which is produced by the sensor is frequency modulated on carrier signals.

Then the signal is transmitted through air. The signal is demodulated on the receiving side. This type of transmission is economically viable for all formers. Level sensors are placed for every individual field.

\section{Rain Sensors}

Rain sensors have the same concept of the level sensors. This sensor is more intelligent when compare to the level sensors. Rain sensors signal can be transmitted through the same ways which are mentioned in the level sensors. In this sensor two contacts are placed very closely. If the rain water droplet closes the small gap between the contacts then the sensor circuit will be closed and the signal will be transmitted to the PLC control unit.

\section{Water Flow Control}

Water flow control is the main part of the irrigation process which needs man power in the conventional method. But in this system we have controlled the water flow using solenoid valves is shown in figure 2. Solenoid valve is used as a switch which closes or opens the water flow in the pipe. Solenoid valve has been classified as two types.

1. Normally open type

2. Normally closed type

In the first type solenoid valve the coil is normally in closed mode. It changes it's mode during the signal arrival. It has two types which are classified by direction of current. In this system we have used the A. C 230V solenoid valve.

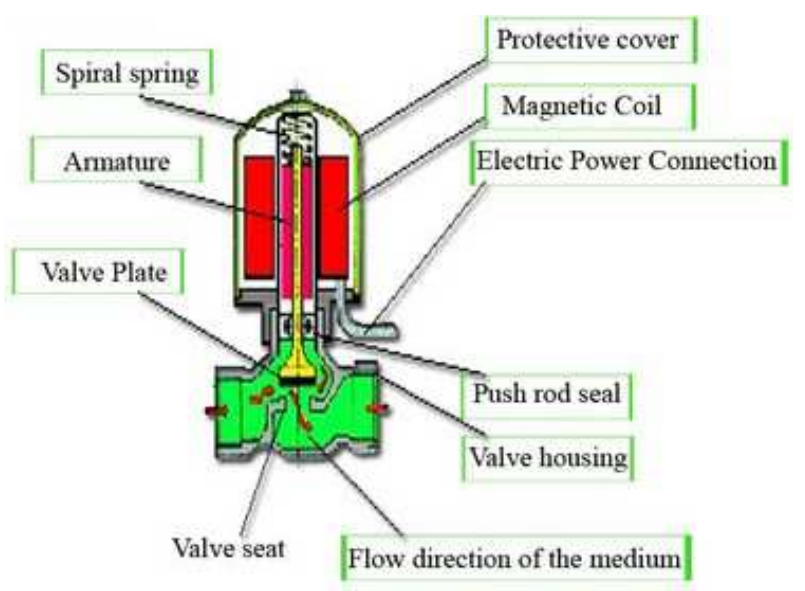

Figure 2. Water Flow Control.

Solenoid valves are placed for every field. When the signal from the sensor is reached to PLC, then the PLC switches the corresponding solenoid valve. Then the water flows through the solenoid valve to next field. If the next field sensor is sensed, then the previous solenoid valve is closed and the next will be opened by the PLC.

\section{PLC Control Unit}

All signals which are transmitted by the sensors are received in the PLC control unit. PLC has a combination of relay switches which are turned on or off by some logic. PLC is nothing but an intelligent system which is used as a switch for many devices. PLC (PROGRAMMABLE LOGIC CONTROLLER) is programmed by using assembled language. Before the advent of solid-state logic circuits, logical control systems were designed and built exclusively around electromechanical relays. Relays are far from obsolete in modern design, but have been replaced in many of their former roles as logic-level control devices, relegated most often to those applications demanding high current and/or high voltage switching.

Systems and processes requiring "on/off" control abound in modern commerce and industry, but such control systems are rarely built from either electromechanical relays or discrete logic gates. Instead, digital computers fill the need, which may be programmed to do a variety of logical 
functions. The purpose of a PLC was to directly replace electromechanical relays as logic elements, substituting instead a solid-state digital computer with a stored program, able to emulate the interconnection of many relays to perform certain logical tasks. A PLC has many "input" terminals, through which it interprets "high" and "low" logical states from sensors and switches. It also has many output terminals, through which it outputs "high" and "low" signals to power lights, solenoids, contactors, small motors, and other devices lending themselves to on/off control. In an effort to make PLCs easy to program, their programming language was designed to resemble ladder logic diagrams.

Thus, an industrial electrician or electrical engineer accustomed to reading ladder logic schematics would feel comfortable programming a PLC to perform the same control functions. PLCs are industrial computers, and as such their input and output signals are typically 120 volts AC, just like the electromechanical control relays they were designed to replace. Although some PLCs have the ability to input and output low-level DC voltage signals of the magnitude used in logic gate circuits, this is the exception and not the rule. Signal connection and programming standards vary somewhat between different models of PLC, but they are similar enough to allow a "generic" introduction to PLC programming here.

The following illustration shows a simple PLC, as it might appear from a front view. Two screw terminals provide connection to 120 volts $\mathrm{AC}$ for powering the PLC's internal circuitry, labeled L1 and L2. Six screw terminals on the lefthand side provide connection to input devices, each terminal representing a different input "channel" with its own "X" label. The lower-left screw terminal is a "Common" connection, which is generally connected to L2 (neutral) of the $120 \mathrm{VAC}$ power source. Inside the PLC housing, connected between each input terminal and the Common terminal, is an opto-isolator device (Light-Emitting Diode) that provides an electrically isolated "high" logic signal to the computer's circuitry (a photo-transistor interprets the LED's light) when there is $120 \mathrm{VAC}$ power applied between the respective input terminal and the Common terminal. An indicating LED on the front panel of the PLC gives visual indication of an "energized" input is shown in figure 3:

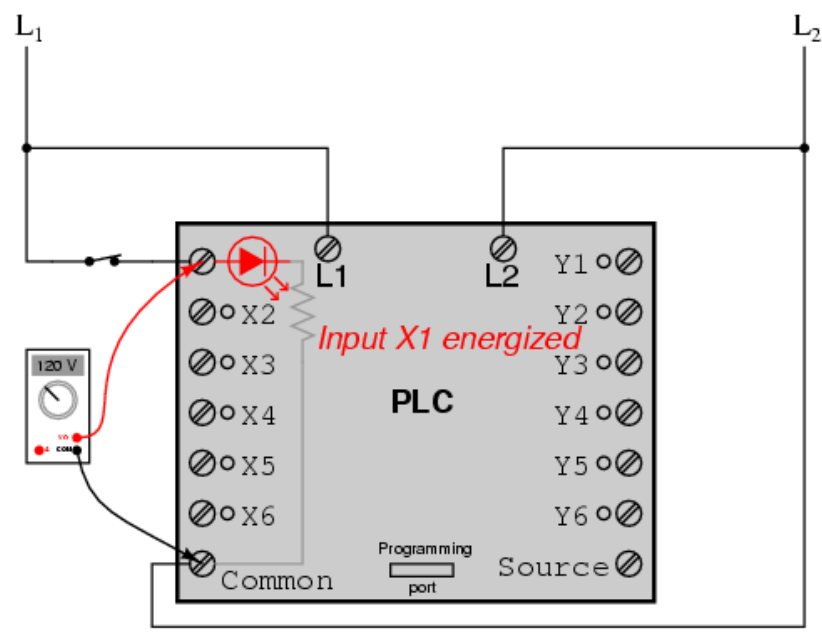

Figure 3. Energized Input.
Output signals are generated by the PLC's computer circuitry activating a switching device (transistor, TRIAC, or even an electromechanical relay), connecting the "Source" terminal to any of the "Y-" labeled output terminals. The "Source" terminal, correspondingly, is usually connected to the L1 side of the 120 VAC power source. As with each input, an indicating LED on the front panel of the PLC gives visual indication of an "energized" output is shown in figure 4:

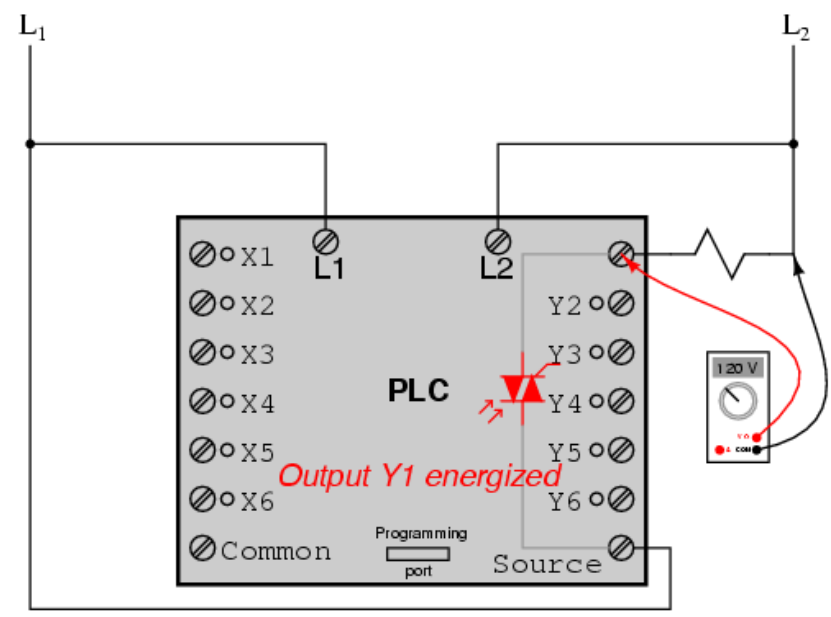

Figure 4. Energized Output.

In this way, the PLC is able to interface with real-world devices such as switches and solenoids. The actual logic of the control system is established inside the PLC by means of a computer program. This program dictates which output gets energized under which input conditions. Although the program itself appears to be a ladder logic diagram, with switch and relay symbols, there are no actual switch contacts or relay coils operating inside the PLC to create the logical relationships between input and output. These are imaginary contacts and coils, if you will. The program is entered and viewed via a personal computer connected to the PLC's programming port.

\section{Working Methodology}

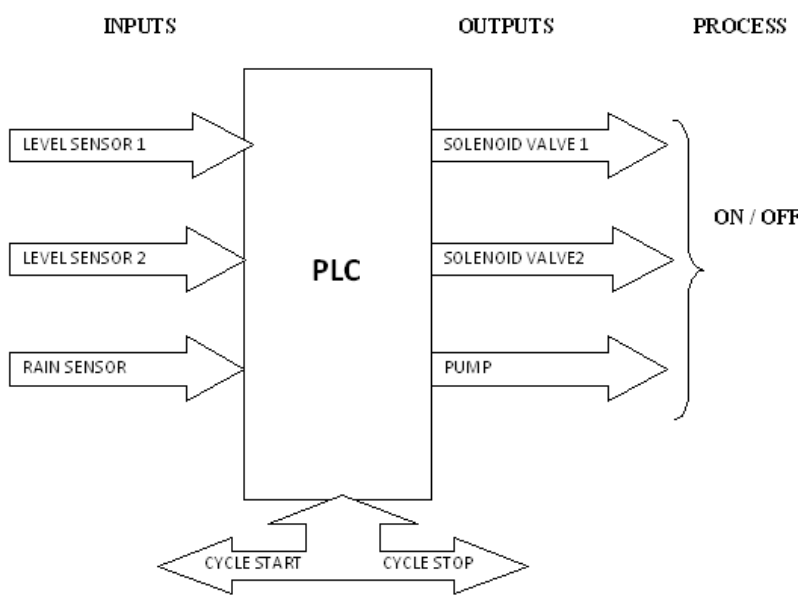

Figure 5. Block Diagram of PLC Process ON/OFF. 
When the cycle start button is pressed, then the plc is switched on and being run the program which was downloaded into the PLC based upon the logic as per our ladder diagram concern is shown in figure 5. As per our program concern first up all the motor is switched on simultaneously with the PLC. Then the first solenoid valve is opened which is placed in the first field. So water flows through this first valve which one irrigates the first field. The first solenoid valve is closed when the signal from the first water level sensor is reached to the PLC. At the same time the second solenoid valve is opened which helps to irrigate the second field up to the required level. After the water level reached in the second field the PLC turns off the pump (consider this event is a last field when we go for large scale irrigation). Whenever there is rain then the rain sensor indicates the signal to the PLC. Automatically the pump is switched off by the PLC. PLC can be switched on or off whenever we want. This concept is achieved by the timers present in the PLC. So we can irrigate the land whenever the water is required is shown in figure 6.

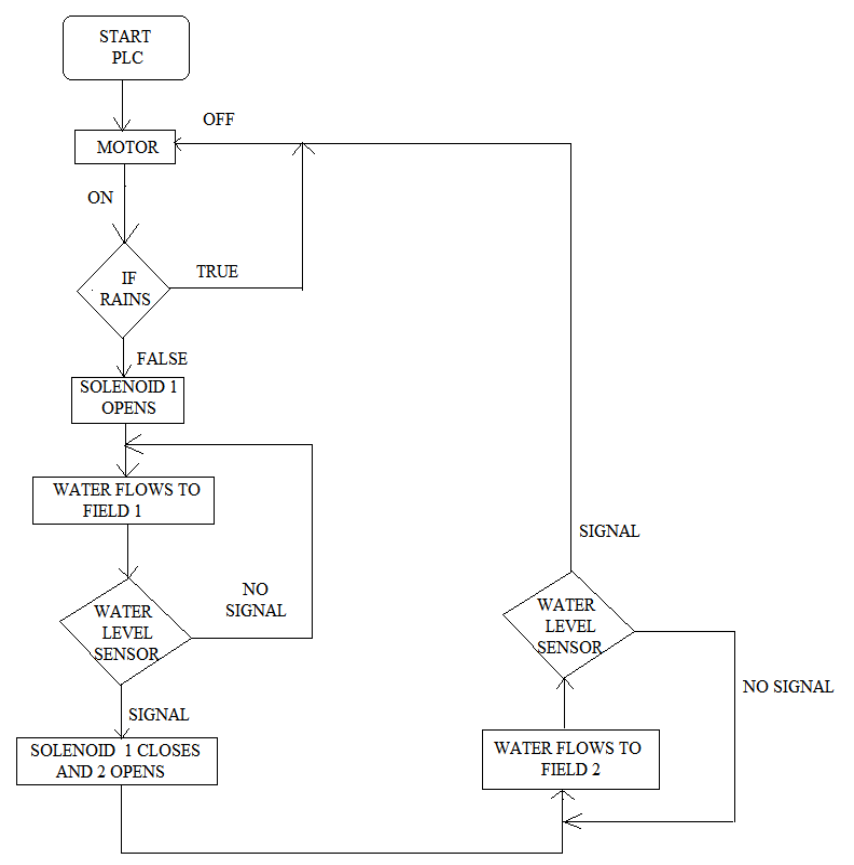

Figure 6. Flow Chart of Water Level Sensor.

\section{Conclusion}

Since the above mentioned system does not require any human interface. This system saves the power as well as the water. It reduces the defects occurring in the pump. It reduces the error which is because of the absence of intellect of human. This system is economically viable for large scale forming as well as small scale forming. The water system framework executed was seen as viable in limiting water utilization in fields. As the water is provided distinctly close to the underlying foundations of the yields and not the whole field, the issue of weeds is killed. Hence checking procedure in farming fields will be a viable technique that will be valuable in circumstances where use of water assets is restricted. By executing this undertaking, there will be a compelling and productive utilization of water assets. The Android application empowers the client to screen the estimations of sensors. The exhibition measures got can be kept up in database which will be helpful for looking at changed yields at various climatic conditions.

\section{References}

[1] K. S. S. Prasad, Nitesh Kumar, Nitish Kumar Sinha and Palash Kumar Saha "Water-Saving Irrigation System Based on Automatic Control by Using GSM Technology" MiddleEast Journal of Scientific Research 12 (12): 1824-1827, 2012.

[2] Sanjukumar, R. V. Krishnaiah "Advance Technique for Soil Moisture Content Based Automatic Motor Pumping for Agriculture Land Purpose" Volume 04, Article 09149; September 2013.

[3] Yunseop (James) Kim, Robert G. Evans, and William M. Iversen, "Remote Sensing and Control of an Irrigation System Using a Distributed Wireless Sensor Network", IEEE transactions on instrumentation and measurement, vol. 57, no. 7, July 2008.

[4] S. Darshna, T. Sangavi, Sheena Mohan, A. Soundharya, Sukanya Desikan, "Smart Irrigation System", IOSR Journal of Electronics and Communication Engineering (IOSR-JECE) eISSN: 2278-2834, p - ISSN: 2278-8735. Volume 10, Issue 3, Ver. II (May - Jun. 2015), PP 32-36 www.iosrjournals.org.

[5] Nagarajapandian M, Ram Prasanth U, Selva Kumar G, Tamil Selvan S, "Automatic irrigation system on sensing soil moisture content", International Journal of Innovative Research in Electrical, Electronics, Instrumentation and Control Engineering vol. 3, issue 1, January 2015.

[6] Indu Gautam and S. R. N Reddy, "Innovative GSM based Remote Controlled Embedded System for Irrigation", International Journal of Computer Applications Vol. 47 - No. 13, June 2012.

[7] Jin Shen, Song Jingling, Han Qiuyan and Yang Yan, "A Remote Measurement and Control System for Greenhouse Based on GSM-SMS", Electronic Measurement and Instruments, 2007. ICEMI '07. 8th International Conference.

[8] Karan Kansara, Vishal Zaveri, Shreyans Shah, Sandip Delwadkar, and Kaushal Jani "Sensor based Automated Irrigation System with IOT: A Technical Review", (IJCSIT) International Journal of Computer Science and Information Technologies, Vol. 6 (6), 2015, 5331-5333.

[9] R. Suresh, S. Gopinath, K. Govindaraju, T. Devika, N. Suthanthira Vanitha, "GSM based Automated Irrigation Control using Raingun Irrigation System", International Journal of Advanced Research in Computer and Communication Engineering Vol. 3, Issue 2, February 2014.

[10] S. Li, J. Cui, Z. Li, "Wireless Sensor Network for Precise Agriculture Monitoring," Fourth International Conference on Intelligent Computation Technology and Automation, Shenzhen, China, March 28-29, 2011.

[11] IEEE, Wireless medium access control (MAC) and physical layer (PHY) specifications for lowrate wireless personal area networks (LR-WPANs). In The Institute of Electrical and Electronics Engineers Inc.: New York, NY, USA, 2003. 
[12] Venkata Naga Rohit Gunturi, "Micro Controller Based Automatic Plant Irrigation System" International Journal of Advancements in Research \& Technology, Volume 2, Issue-4, April-2013.

[13] Dr. V. Vidya Devi, G. Meena Kumari, "Real- Time Automation and Monitoring System for Modernized Agriculture", International Journal of Review and Research in Applied Sciences and Engineering (IJRRASE) Vol3 No. 1. PP 7-12, 2013.
[14] Muhamad Azman Miskam, Azwan bin Nasirudin, Inzarulfaisham Abd. Rahim; "Preliminary Design on the Development of Wireless Sensor Network for Paddy Rice Cropping Monitoring Application in Malaysia"; European Journal of Scientific Research ISSN 1450-216X Vol. 37No. 4, 2009. 